\title{
Desarrollo social, factor de mitigación de la criminalidad en el Pacífico colombiano
}

\author{
Social Development, Crime Mitigation Factor in the Colombian Pacific
}

DOI: https://doi.org/10.21803/penamer.14.27.351

Juan Pablo Serrano Guzmán

http://orcid.org/0000-0003-1048-0389

Norman Tejada Sánchez

https://orcid.org/0000-0002-8885-2392

¿Cómo citar este artículo?

Serrano, J. \& Tejada, N. (2021). Desarrollo social, factor de mitigación de la criminalidad en el Pacífico colombiano. Pensamiento Americano, 14(27), 95114. DOI: https://doi.org/10.21803/penamer.14.27.351

\section{Resumen}

Objetivo: La región Pacífico colombiano es una zona de conflicto entre el contrabando ilegal del narcotráfico y la convivencia de grupos armados al margen de la ley. Hasta la fecha el Estado ha promovido en su política de seguridad un desenvolvimiento de acciones militares y policiales para enfrentar este fenómeno dentro de su agenda una política antidroga. No obstante, las condiciones de subdesarrollo en la región son multiplicadores de la amenaza y los medios para conseguir la superación de esta no han sido efectivos. Objetivo: En este estudio se plantea que las acciones tendientes a promover el desarrollo social, sin contar con las vías prohibicionistas o legalistas hacia las drogas que se asuman, permitirá a los habitantes decidir entre la legalidad o ilegalidad, por cuanto se generarán oportunidades de integración regional. De tal forma, se podrá pasar del control militar al control institucional del territorio. Método y metodología: Esta investigación de tipo descriptiva y cualitativa es poder llegar a comprender que los problemas que circulan en la región pacífica no solo se trata de una aplicación de la fuerza para devolver la seguridad al territorio, sino también de la necesidad de una integralidad de soluciones con factor social que devuelva ese tejido a la pertenencia nacional con miras al desarrollo. Conclusiones y resultados: En tal sentido, se logra percibir que la falta de oportunidades en un entorno social deprimido requiere de atención especial del gobierno para fundamentar un cambio de cultura de la ilegalidad como medida de esperanza y recuperación social.

Palabras Clave: Maternaje; Discapacidad; Repercusiones.

\begin{abstract}
:
Objective: The Colombian Pacific region is a zone of conflict between the illegal smuggling of drug trafficking and the coexistence of illegal armed groups. To date, the State has promoted in its security policy a development of military and police actions to address this phenomenon within its antidrug policy agenda. However, the conditions of underdevelopment in the region are multipliers of the threat and the means to overcome it have not been effective. Objective: In this study it is proposed that actions aimed at promoting social development, without relying on prohibitionist or legalistic routes towards drugs that are assumed, will allow the inhabitants to decide between legality or illegality, as opportunities for regional integration will be created. In this way, it will be possible to move from military control to institutional control of the territory. Method and methodology: This descriptive and qualitative research are to be able to understand that the problems circulating in the peaceful region are not only an application of force to return security to the territory, but also the need for comprehensive solutions with a social factor that returns that fabric to national ownership for development. Conclusions and results: In this sense, it is possible to perceive that the lack of opportunities in
\end{abstract}




\author{
a depressed social environment requires special attention from the \\ government to base a change of culture of illegality as a measure of hope \\ and social recovery. \\ Key words: Drug trafficking; Mitigation; Social development; \\ Substitution; Strategy.

\section{Resumo} \\ aa \\ Palavras-chave: Maternidade; Incapacidade; Repercussões.
}

\title{
Perfiles
}

Oficial Naval de grado Capitán de Corbeta, profesional en Ciencias Navales y Juan Pablo Serrano Guzmán especialista en Política y Estrategia Marítima de la Escuela Naval "Almirante Padilla", Máster en Estrategia y Geopolítica, Armada de Colombia, Bogotá, 96 Colombia. Contacto: juan.serrano@armada.mil.co; serranoj@esdegue.edu.co y serranoguzman@gmail.com.

2 oficial Naval de grado teniente de Navío, profesional en Ciencias Navales y Máster en Logística Integral, Armada de Colombia, Cali, Colombia. Contacto: norman.

Norman Tejada Sánchez tejada@armada.mil.co y normantejadasanchez@gmail.com. 


\section{Introducción}

Según información reportada en el último censo, el Pacífico colombiano cuenta con el $16.79 \%$ de la población del país según el último censo (DANE, 2018a). Esta región alberga un $18.0 \%$ de la población afrodescendiente y el $7.57 \%$ de la población indígena, dispersos en las áreas rurales de los diferentes municipios de la zona. Esta contabilidad de personas muestra que casi 600.000 están localizadas en regiones sin conexión a los centros urbanos y de desarrollo rural, estando así en condiciones de miseria. La ausencia de oportunidades para salir adelante abre el espacio para que la criminalidad sea en algunos casos objeto de supervivencia regional a pesar de que existe agricultura, ganadería, minería, turismo, pesca y actividades portuarias y el motivo es que han proliferado los cultivos ilícitos para producción de clorhidrato de cocaína, los cuales son manejados por las empresas criminales.

La presente investigación es mixta, al ser descriptivo con análisis cualitativo y cuantitativo, donde de manera reflexiva muestra las posibilidades de superación de la región en camino a un desarrollo social y sostenible, postulando que de esta forma pueda mitigarse el interés que pueda existir en las comunidades para optar por la oferta laboral de la criminalidad y al mismo tiempo, reducir la pobreza ante una oferta legal de trabajo, producto de la incorporación de los municipios del litoral al centro de poder administrativo y político, por encima de la geografía y la visión geopolítica centralista.

El recorrido ofrece al lector obtener una visión de primera mano por medio de diferentes estudios de instituciones, organizaciones y particulares, que han dado a conocer la real situación que allí se percibe para luego aceptar la posibilidad de incluir al desarrollo social como un factor determinante en la mitigación del narcotráfico dentro de la política de lucha antidrogas. Se parte del hecho al entender que la dinámica de comunicación de la región hacia el centro de mando nacional se hace por medio de dos carreteras que llevan y traen el desarrollo; introducen a la región en el comercio marítimo mundial a través del puerto de Buenaventura en el departamento del Valle del Cauca y de allí tomando la única arteria existente hacia Cali y posteriormente al resto de la región occidental y central por las vías hacia Pasto, Medellín y Bogotá. La otra arteria existente, se considera como vía principal, pero tiene tramos complicados y disminuidos para generar la interconexión, es la carretera de San Andrés de Tumaco a Pasto. Son desde el siglo $\mathrm{XX}$, las únicas vías que comunican la región con todas las regiones del país.

La geopolítica del Pacífico no le favorece a la región para alcanzar la importancia que como región tiene ante un alto potencial productivo. La zona está apartada de la capital por las cordilleras, de tal forma que éstas sirven como un muro de Berlín que sólo se derrumba en etapas electorales. Esta división administrativa y geográfica, muestra que la región del litoral es la más afectada, los indicadores de necesidades básicas insatisfechas y de desarrollo humano están por debajo de la media del país y de la capital, además de deficiencias en salud, educación e infraestructura, por lo que la criminalidad cuenta con facilidad para unir a los habitantes en torno a conformar un grupo armado, una estructura criminal o una organización de narcotráfico por el simple hecho de falta de oportunidades y deseo de solventar las necesidades (Aragón, 2010; Alcaldía de Tumaco, 2018).

Esto indica que, de tomarse una vía legalista o de normalización de las drogas que causan dependencia en el país, se afectará la pirámide salarial ilegal y en ausencia de oportunidades de educación, salud e infraestructura o un empleo estable y digno, es un detonante que puede llegar a engrosar las filas de la ilegalidad. De otro lado, si se continúa la prohibición sin haber invertido en la región para incrementar el desarrollo social, permanecerá la delincuencia debido al mismo a que no hay oportunidades.

Tras los acuerdos del posconflicto firmados con la guerrilla más vieja del mundo, el gobierno de Colombia proyectó soluciones al problema de las drogas con proyectos alternos de sustitución de cultivos y planes 
de infraestructura, los cuales no han sido del todo eficientes en comparación a los realizados por otros países como Ecuador o Perú, donde los cultivadores de hoja de coca hoy en día son comerciantes de cacao y productos pesqueros. Se trata de una estrategia multisectorial que permitirá el ingreso de las Fuerzas Armadas como un promotor de seguridad y estabilidad, el ingreso de la gobernabilidad del centro de poder nacional a los municipios del Pacífico colombiano donde será reconocido y legítimo por su gestión que ayudó a la población a suplir sus necesidades a través de diferentes proyectos y, será un cambio de la contracultura existente del narcotráfico a través de una población sana y educada con principios y valores. Todo esto no solo será un factor de riesgo para la criminalidad por un incremento de la consciencia social, será el verdadero paso del control militar del territorio al control institucional que requiere el Plan Nacional de Desarrollo.

\section{Desarrollo Social, factor de mitigación de la criminalidad en el Pacífico colombiano}

La legalización, normalización o descriminalización de la droga como objeto para conseguir una disminución, no mitigación, de las ganancias producto del lavado de activos por las transacciones ilegales son insuficientes ante unas condiciones que el país no puede sostener (Garzón, 2015). Caso contrario si a la función prohibicionista se le refuerza y se le agrega un componente que es para tanto para la legalización como para la persecución directa de las drogas un elemento multiplicador como las vías de desarrollo, genera oportunidades a la población en la toma de decisiones entre la legalidad y la ilegalidad. De un lado, habría una recomposición del tejido social que en caso de aceptarse una doctrina legalista habría un sustento que suplante la economía ilegal y por el otro, ante una ley robusta y unos medios eficientes servirá de manera disuasiva como refuerzo ante la opción de captura, esto debido a que el ciudadano puede tener una opción legal ante la oportunidad criminal.

En este orden de ideas, entendiendo al Pacífico colombiano como una región en la que el desarrollo consiste en dos carreteras que conducen de Cali a Buenaventura y de Cali a Tumaco, dejando el resto de la región en comunicación fluvial, se hace necesario disminuir la miseria y la pobreza ante el atraso existente, para lograr de esta manera una verdadera mitigación al reclutamiento ilegal de trabajadores de las drogas y de los grupos armados organizados, pues como dice Villamizar (2020), la inseguridad modifica las condiciones de vida de las personas ante un debilitamiento de la institución Estado como promotor de beneficios a la población, además que con la violencia, existe mayor dificultad de generar desarrollo ante la percepción de riesgo. Dentro de estas necesidades o más bien, escasez de medios para el progreso en la región Pacífico, se puede evidenciar que en la gestión pública (Head, 2008), se hace indispensable contar con mejores medios de control para evitar desviaciones o corrupción. En estudio que realizó un grupo de docentes de la Universidad Javeriana de Cali en proceso de verificación para una revista en Puerto Rico, sirve para conocer los alcances del subdesarrollo en la criminalidad, y así lograr delimitar el área de análisis en esta investigación, considerando la Zona de Manejo Especial que corresponde al municipio de Tumaco (Nariño), en razón que después de Buenaventura, es el municipio con mayor desarrollo del litoral donde la Armada de Colombia ejerce el dominio del control del mar.

En ambientación, para el año 2011 a través de la necesidad del Estado de afectar tangencialmente el problema de las drogas, ante la medida de restringir la aspersión aérea, se optó por la erradicación manual forzosa y/o voluntaria en procura de cumplir lo establecido en la Política Nacional de Consolidación del Territorio (Observatorio de Drogas de Colombia y Minjusticia, 2014). Es desde esta fecha que los cultivos ilícitos se empiezan a incrementar, se contaba con 63.762 hectáreas cultivadas y a pesar de erradicar 34.170 hectáreas, hubo una resiembra del $34 \%$, donde se sumaron 2200 laboratorios de pasta/base de cocaína y 200 de clorhidrato de cocaína según puede contarlo así el Sistema Integrado de Monitoreo de Cultivos Ilícitos de la fecha (UNODC, 2012).

Para el año 2018, se pudo observar un crecimiento

Pensamiento Americano Vol. 14 - No. 27 - p.p. 95-114 • 2021 • Enero-Junio · Corporación Universitaria Americana • Barranquilla, Colombia • ISSN-e: 2745-1402 $\mathrm{http}$ //publicaciones.americana.edu.co/index.php/pensamientoamericano/index 
exponencial alcanzando las 169.000 hectáreas, esto significó un incremento del 65\% (UNODC, 2019), conduciendo a un cambio de política a través de las llamadas "Ruta Futuro: Política Integral para Enfrentar el Problema de las Drogas 2018-2022” que consiste en reducir el consumo de sustancias psicoactivas, el tráfico interno y externo, desarticulación de estructuras criminales y lograr un efecto contra el lavado de activos y todas las economías que emerjan de la ilegalidad producto de las drogas. Y es en el Pacífico colombiano, específicamente en la región de Nariño donde se encuentra el municipio de Tumaco, ser notado como uno de los diez municipios con mayor concentración de cultivos de uso ilícito acompañado en el área departamental con el Charco y Barbacoas y en el resto del país con Tibú, Norte de Santander; Puerto Asís, Putumayo; El Tambo, Cauca; Sardinata, Norte de Santander; El Tarra, Norte de Santander; Orito, Putumayo y Tarazá, Antioquia; además de lo aquí descrito, los municipios con mayor concentración de cultivos en el departamento de Nariño equivalen al $17 \%$ de los municipios de Colombia que aportan el $44 \%$ de los cultivos de coca del país (UNODC, 2019).

Dejando aparte la relación con los cultivos ilícitos, para poder llegar a entender la dinámica del desarrollo social en la región como motor de un cambio de cultura, se hace necesario entender el comportamiento en otros aspectos. Sánchez y Caballero (2019), tras un estudio dan cuenta que Nariño con relación al Índice de Desarrollo Humano (IDH), ha tenido un menor desempeño debido a: "los bajos ingresos per cápita, dificultad en acceso a salud y educación” (p. 9), cuyo promedio está por debajo del promedio nacional y si se parte del proceso educativo, también ocupa los últimos lugares llegando a pertenecer al grupo del $11 \%$ del país que adolece de altos estándares.

Para Naciones Unidas, mide el IDH con base a la esperanza de vida al nacer, escolaridad y el ingreso bruto per cápita. Para el caso de Tumaco, con base al análisis de la situación de salud realizado por la Secretaría de Salud Municipal (Alcaldía de Tumaco, 2018), con relación a las tasas de mortalidad materno-infantil en el marco de estudio de 2005 a 2017, sus indicadores están por debajo del promedio en contraste al departamento, por ejemplo; para el caso de la tendencia de la mortalidad materna corresponde a 165,95 defunciones por cada cien mil habitantes contra 140,42 del departamento; sobre mortalidad infantil el departamento tiene 12,36 muertes por cada cien mil habitantes contra 17,29 que tiene el municipio; de interés, los mayores índices los albergan las comunidades indígenas que para el 2016 murieron 27 recién nacidos por cada 1000 niños en contraste a las etnias negras, mulatas, afrocolombiana o afrodescendientes con 9,13, indicadores de interés para una población total de acuerdo al censo realizado en 2018 de 212.692 habitantes, notando así que $80.19 \%$ son afrodescendientes para 174.194 habitantes y solo $4.59 \%$ son indígenas para 9.762 habitantes (DANE, 2018a), con esto decir que a pesar de contar con acceso al sistema de salud porque las estadísticas del Sisbén indica que incorpora 27.188 personas en el área rural, se requiere mayor acceso al servicio y mayor información del mismo para intentar persuadir las razones culturales que puedan existir.

Para seguir componiendo el conocimiento sobre el IDH en Tumaco, pasando al nivel de escolaridad, componente esencial para modificar la cultura de la sociedad y de esta manera proyectar el espíritu de superación con miras hacia la legalidad, el Banco de Desarrollo de América Latina y el Instituto de Ciencia Política Hernán Echavarría Olozaga (ICP, 2018), identifica al municipio como un reto, pues la tasa de analfabetismo es del $11 \%$, siendo más alta en áreas rurales para $16 \%$; además de esto, el $43,5 \%$ apenas alcanza la educación básica primaria y solo llegan a un nivel de educación superior del 4,7\%, donde el $18 \%$ no estudia; para tener una idea, la tasa de analfabetismo del país es del 5,24\% (Mineducación, 2018). El informe aprecia que las razones a que ocurra esto es porque: "Esta problemática está relacionada con la inexistencia de la infraestructura adecuada para asegurar el acceso a los centros educativos. La población joven no encuentra condiciones para garantizar su tránsito a la educación superior" (p. 46). Por lo tanto, no se puede esperar contar con un adecuado control institucional del territorio como dicta el Plan Nacio- 
nal de Desarrollo (Presidente de la República, 2018). La juventud se encuentra en riesgo ante este escenario, no cuenta con garantías educativas y oportunidades laborales al término de un bachillerato, se espera que entren a hacer parte de la lista de desempleados sumando alrededor de 25.000 personas, quienes, si no consiguen empleo legal o informal, pueden ser seducidos por los grupos armados ilegales y el narcotráfico como sustento.

Pasando a los ingresos del municipio, Tumaco tiene altos gastos de funcionamiento, deterioro de ahorro corriente e inversión, cuyo desempeño fiscal es del 23.1 puntos negativos dentro del lapso 2014-2015 (DNP, 2015a). Esto a pesar de que tiene un potencial de desarrollo comercial no explotado por contar con un puerto que es el segundo en importancia en la región Pacífico, también tiene problemas para la gestión de residuos, siendo capaz de producir 88kilos de basura por habitante, problemas de deforestación por el problema de drogas perdiendo en los años 2017 y 2018 un total de 7.881 hectáreas aprovechables y, además, una amenaza muy alta ante los efectos del cambio climático. Saliendo de esos parámetros estadísticos que caracteriza la zona, su actividad comercial es el intercambio con Ecuador, todo esto para decir que en el lapso de 2014 al 2018, el departamento tuvo un Producto Interno Bruto (PIB) per cápita de 7,5 millones de pesos corrientes en comparación a los 17,7 millones de pesos del país, cuya actividad económica legal se centra en la agricultura, minería y manufacturas (Parra, Higuera y Rodríguez, 2019). Con esto hay que aclarar que la región cuenta con capacidad de producir, pero no evoluciona.

Entonces, se debe buscar el desarrollo de la región para mitigar la violencia y el narcotráfico. El Banco Mundial (2014) así lo determina tras una evaluación a 2000 personas en México:

En primer lugar, es importante que los gobiernos consigan consolidar los logros alcanzados en la última década en cuanto a reducción de la pobreza, desigualdad y desempleo. Para esto es fundamental seguir promoviendo el crecimiento económico y la implementación de políticas sociales para asistir a los hogares más vulnerables. En este sentido, es necesario mantener a los jóvenes en el mercado laboral y reducir los niveles de deserción escolar en la educación secundaria en algunos países para evitar que los adolescentes corran el riesgo de involucrarse en actividades delictivas. También es útil aprender de la experiencia de los países desarrollados (...)

El Programa para el Desarrollo Humano de las Naciones Unidas determinó que el Índice de Pobreza Multidimensional (IPM) va ligado al IDH, pues utiliza microdatos para medir las carencias en los hogares con relación a la salud, la educación y el nivel de vida, pero difiere en el sentido que no mide la desigualdad de manera general, sino que a través de una encuesta determina en un solo hogar, si es pobre o no lo es; sus estudios llevan a comprender estos factores a través de 1.500 millones de personas encuestadas en 101 países, es decir, el $29 \%$ de la población mundial (UNDP, 2020). En Tumaco, con base en el censo de 2018 (DANE, 2019), se logró medir el nivel de pobreza multidimensional, el cual tuvo un ponderado de 53,7 puntos porcentuales, si para Colombia era de 19,1; indica que el municipio es altamente pobre; sus indicadores fueron:

Tabla 1.

Comparación IPM entre Bogotá D.C. y Tumaco.

\begin{tabular}{lcc}
\hline \multicolumn{1}{c}{ Privaciones por variable } & $\begin{array}{c}\text { Total } \\
\text { Tumaco }\end{array}$ & $\begin{array}{c}\text { Total } \\
\text { Bogotá }\end{array}$ \\
\hline Analfabetismo & 19,5 & 2,8 \\
\hline Bajo logro educativo & 61,7 & 26,2 \\
\hline $\begin{array}{l}\text { Barreras a servicios para cuidado de } \\
\text { la primera infancia }\end{array}$ & 3,9 & 1,8 \\
\hline $\begin{array}{l}\text { Barreras de acceso a servicios de } \\
\text { salud }\end{array}$ & 4,1 & 4,3 \\
\hline Tasa de dependencia & 43,9 & 18,9 \\
\hline Hacinamiento crítico & 8,6 & 5,6 \\
\hline Inadecuada eliminación de excretas & 73,1 & 0,7 \\
\hline Inasistencia escolar & 6,3 & 1,9 \\
\hline $\begin{array}{l}\text { Material inadecuado de paredes } \\
\text { exteriores }\end{array}$ & 25,4 & 0,3 \\
\hline Material inadecuado de pisos & 3,0 & 0,3 \\
\hline Rezago escolar & 23,1 & 11,5 \\
\hline $\begin{array}{l}\text { Sin acceso a fuente de agua } \\
\text { mejorada }\end{array}$ & 58,3 & 0,5 \\
\hline Sin aseguramiento en salud & 19,5 & 18,7 \\
\hline Trabajo infantil & 2,5 & 0,5 \\
\hline Trabajo informal & 91,6 & 60,1 \\
\hline $\begin{array}{l}\text { Fuente: Elaboración propia con datos del Censo Nacional de } \\
\text { Población y Vivienda 2018. }\end{array}$ &
\end{tabular}


En este orden de ideas y con el ánimo de visualizar el nivel de desarrollo, el municipio de Tumaco en comparación a la capital del país se encuentra en subdesarrollo, toda vez que Bogotá tiene $3.485,3 \%$ más población. Tomando solo el analfabetismo, las barreras de acceso a servicios de salud y el trabajo informal, las odiosas diferencias permiten comprender la razón por la cual San Andrés de Tumaco, aún permanece con el narcotráfico como vía ilegal para mejorar las condiciones de vida de sus familias. Anteriormente se mencionó que el municipio era un productor de toneladas de basura y si se le suma la inadecuada eliminación de excretas, realmente está sumido en un ambiente tóxico. Posiblemente hubiese sido entendible si los valores fueran opuestos, pues es de mayor cuidado y complicación satisfacer las necesidades de más de siete millones de habitantes.

Entrando a las Necesidades Básicas Insatisfechas (NBI) como puede observarse en la Tabla 2, tomando las estadísticas del Censo 2018 (DANE, 2018b), se puede evidenciar que, en comparación con la capital del país, San Andrés de Tumaco es un foco de inestabilidad para la gobernanza ante el incremento de las necesidades básicas que no han sido cumplidas.

Tabla 2.

Necesidades básicas insatisfechas entre Tumaco y Bogotá D.C.

\begin{tabular}{lcc}
\hline \multicolumn{1}{c}{ Indicador } & Tumaco & $\begin{array}{c}\text { Bogotá } \\
\text { D.C. }\end{array}$ \\
\hline Personas en NBI (\%) & 27,52 & 3,36 \\
\hline Personas en miseria & 6,26 & 0,24 \\
\hline Componente vivienda & 3,12 & 0,36 \\
\hline Componente servicios & 17,02 & 0,10 \\
\hline Componente hacinamiento & 4,44 & 1,35 \\
\hline Componente inasistencia & 3,21 & 1,01 \\
\hline $\begin{array}{l}\text { Componente dependencia } \\
\text { económica }\end{array}$ & 7,91 & 0,79
\end{tabular}
económica

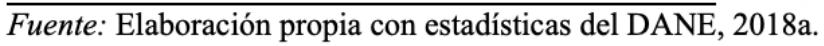

En condición de miseria atendiendo la cantidad de población que tiene cada municipio, Bogotá tendría 14.826 habitantes en contraste con Tumaco que tendría 13.314, una diferencia de 1.511 personas supone pensar que todo el desarrollo del país se enfoca en las ciudades principales. Nuevamente se reitera, en con- diciones tan altas de necesidad, le es fácil al narcotráfico acercarse a las regiones vulnerables y ofrecer la suerte que se divide entre captura o entrega segura de drogas en Centroamérica a cambio de dinero para resolver su situación económica.

Pasando al departamento de Nariño y más cerca de la jurisdicción de la Armada de Colombia donde la Brigada de Infantería de Marina No. 4 proyecta sus operaciones de presencia militar de área dentro y fuera del municipio de San Andrés de Tumaco y, también el área operacional de la Estación de Guardacostas de ese municipio, dentro del cumplimiento de sus funciones deben transitar por los municipios de El Charco, La Tola, Mosquera, Olaya Herrera, Francisco Pizarro y San Andrés de Tumaco, para lograr una idea de lo que representan estos municipios dentro de la jurisdicción que cuenta la estructura militar con relación a la situación de NBI, se hará un comparativo con Bogotá. Este ejercicio permitirá entender el ambiente operacional al que la Fuerza Pública se somete y por más condiciones de seguridad puedan ofrecer, ante una ausencia de vías de desarrollo, no será superada la criminalidad. No obstante, los militares pueden ser la puerta del Estado para la inclusión social. En este orden de ideas, las NBI de los municipios nombrado son:

Tabla 3.

Necesidades Básicas Insatisfechas en municipios costeros de Nariño y Bogotá.

\begin{tabular}{lcccccccc}
\hline Indicador & $\begin{array}{c}\text { Tumac } \\
\mathbf{0}\end{array}$ & $\begin{array}{c}\text { El } \\
\text { Charc } \\
\mathbf{0}\end{array}$ & $\begin{array}{c}\text { La } \\
\text { Tola }\end{array}$ & $\begin{array}{c}\text { Mosquer } \\
\mathbf{a}\end{array}$ & $\begin{array}{c}\text { Olaya } \\
\text { Herrer } \\
\mathbf{a}\end{array}$ & $\begin{array}{c}\text { Fra. } \\
\text { Pizarr } \\
\mathbf{0}\end{array}$ & $\begin{array}{c}\text { Prom } \\
\text { Mcpi } \\
\mathbf{0}\end{array}$ & $\begin{array}{c}\text { Bogot } \\
\text { á D.C. }\end{array}$ \\
\hline $\begin{array}{l}\text { Personas en } \\
\text { NBI (\%) }\end{array}$ & 27,52 & 57,83 & 82,3 & 78,95 & 77,11 & 49,73 & 57,84 & 3,36 \\
\hline $\begin{array}{l}\text { Personas en } \\
\text { miseria }\end{array}$ & 6,26 & 14,29 & $\begin{array}{c}19,2 \\
7\end{array}$ & 8,17 & 15,80 & 8,71 & 12,08 & 0,24 \\
\hline $\begin{array}{l}\text { Componente } \\
\text { vivienda }\end{array}$ & 3,12 & 5,05 & 5,49 & 1,73 & 3,49 & 0,87 & 3,29 & 0,36 \\
\hline $\begin{array}{l}\text { Componente } \\
\text { servicios }\end{array}$ & 17,02 & 46,09 & $\begin{array}{c}78,2 \\
5\end{array}$ & 76,12 & 68,93 & 41,25 & 54,61 & 0,10 \\
\hline $\begin{array}{l}\text { Componente } \\
\text { hacinamiento }\end{array}$ & 4,44 & 6,28 & 4,79 & 1,21 & 5,72 & 1,6 & 4 & 1,35 \\
\hline $\begin{array}{l}\text { Componente } \\
\text { inasistencia }\end{array}$ & 3,21 & 5,52 & 3,40 & 2,56 & 5,38 & 3,43 & 3,91 & 1,01 \\
\hline $\begin{array}{l}\text { Componente } \\
\text { dependencia } \\
\text { económica }\end{array}$ & 7,91 & 12,45 & 13,6 & 6,51 & 12,83 & 13,03 & 11,05 & 0,79 \\
\hline
\end{tabular}

Fuente: Elaboración propia con las estadísticas del Censo, 2018a.

La Tabla 3 indica que no existe ningún municipio del departamento de Nariño en la región costera que 
supere a la capital del país en algún indicador, ni siquiera la media alcanza a superar el subdesarrollo en condiciones de vida. Sin embargo, pensando que San Andrés de Tumaco es el segundo puerto en importancia en el Pacífico, las condiciones que presenta el municipio de Francisco Pizarro en cuanto al tema de vivienda, son mejores a pesar de estar incomunicados por carreteras y contando solo con los ríos y el mar para desarrollo, no obstante, podría asumirse que se trata de la influencia de economías ilegales, así lo determinó el Observatorio de Drogas de Colombia (ODC, 2016):

Puntos de embarque en el Pacífico: buena parte de la cocaína producida en la zona Pacífico del departamento, en los municipios comprendidos entre Francisco Pizarro y Santa Bárbara, al norte de la zona, son embarcadas en lanchas rápidas directamente en el Pacífico. (p. 17)

También se permite agregar, que en el año 2007 los cultivos tuvieron un mayor valor, donde se expandía el área cultivada de la zona rural del municipio de Francisco Pizarro (ODC, 2016).

Hasta ahora, se ha podido percibir que la muestra en cuanto a municipios que cubren el Pacífico, con excepción de Buenaventura porque en ella está el máximo puerto marítimo sobre el Pacifico, la condición natural ha sido de una percepción de abandono en cuanto a cubrir las necesidades de la población, posiblemente por la incomunicación que existe con el centro de mando del gobierno en Bogotá, esto se debe a la falta de conciencia geográfica. Para explicarlo, Aragón (2010) emplea definiciones de Bahamón cuando menciona que las cordilleras representan un obstáculo al desarrollo, anatomía del país que funcionan como una muralla que impide mirar al océano como parte integral de la evolución como país, dice:

Estas características geográficas de Colombia generan una limitación para el Estado forjando como principal consecuencia una no integración y obstaculización del desarrollo nacional. Sólo llegaremos a la integración por las vías terrestres. Así mismo, la ausencia de integración ha llevado a que esas zonas del territorio donde no se tiene control por parte del Estado, la guerrilla se posesione e implante su propio poder. (p. 15).

Por lo tanto, el Pacífico requiere de una conexión no solo con el interior sino entre regiones más allá del tránsito por ríos, de esta manera alcanzar un desarrollo en infraestructura que sea llamativo a la industria y, sobre todo, mejorar la movilidad para la seguridad de la población, Aragón (2010) sigue con la siguiente anotación:

En el país no se ha logrado comprender la urgencia de vías de comunicación que conectan todo el territorio, para una integración del heartland y el hinterland ya que lo anterior implica control terrestre. Sin dicho cometido, la pérdida de dominio del espacio se verá incrementada. Se necesita mayor movilidad terrestre, expansión y apoderamiento del territorio (p. 16).

La gobernanza y gobernabilidad, el primero como arte y el segundo como método de ejecución para (González, 2009), requieren de una integración e interconexión entre los centros de poder local con el departamental y nacional, de esta manera acercar las vías de desarrollo y disminuir el tiempo de intervención. Acudiendo a los proyectos de infraestructura vial que ofrece el portal web del Ministerio de Transporte (2020), se observa que de 86 proyectos para el país, el departamento de Nariño cuenta con cuatro de ellos, dos buscan la rehabilitación al aeropuerto de Pasto, finalizar la carretera que comunica a Tumaco y Pasto con Ecuador en Tulcán y San Lorenzo y, mejorar la carretera de Rumichaca a Pasto; con relación al cumplimiento de éstos, el aeropuerto de Pasto va al $87 \%$ de finalización y la carretera de Rumichaca al $50 \%$. Como dato adicional, dentro de los proyectos estratégicos que tiene el país, no se encontró incluido alguno de la región Pacífico nariñense. Si bien el proyecto que se relaciona indicando la carretera hacia Ecuador afecta positivamente al municipio de Tumaco, el paso se realiza en La Espriella sobre el río Mataje, lejos de la jurisdicción de la Armada de Co-

Pensamiento Americano Vol. 14 - No. 27 - p.p. 95-114 • 2021 • Enero-Junio • Corporación Universitaria Americana • Barranquilla, Colombia • ISSN-e: 2745-1402 
lombia y del centro productivo municipal. Acudiendo al portal del Sistema Electrónico de Contratación Pública (secop i, 2020), le asignaron al municipio de Tumaco para ejecución del año 2020, un total de $\$ 5.232 .424 .202 .605$ en temas de infraestructura vial; durante el actual gobierno, solamente se han licitado en materia de terrenos, edificios, estructuras y vías, nueve proyectos, de los cuales seis se han celebrado, uno ha sido descartado, otro liquidado y finalmente uno terminado por anormalidades después de convocado, contratos que suman apenas $\$ 10.516 .420 .949$, un $0,2 \%$ del total asignado, valor que sería menor ante el descarte y terminación de contratos.

La región Pacífico nariñense, específicamente el municipio de Tumaco ha servido de ejemplo para caracterizar la zona. Se pudo demostrar que el Índice de Desarrollo Humano, el Índice de Pobreza Multidimensional y las Necesidades Básicas Insatisfechas redundan y recalcan las falencias que ubican la región como de las más necesitadas del país. De otra parte, la geopolítica afecta la gobernabilidad ante una geografía que vuelve centralista el Estado y perjudica el desarrollo de la comunidad costera del océano Oeste de Colombia, en donde se profundiza la falta de integración ante ausencia de carreteras que los conecte a las oportunidades. Estos parámetros son los causantes que ayudan a incrementar la desigualdad y promover la delincuencia y criminalidad como medios de vida ante la falta de fuentes legales de ingresos.

Dentro de las alternativas para reducir las brechas entre el desarrollo y el gobierno, debe existir una política multisectorial, de tal forma que si se adopta la vía prohibicionista existan oportunidades para las poblaciones afectadas y vulnerables.

En Perú, la Comisión Nacional para el Desarrollo y Vida sin Drogas (Devida, 2016) con apoyo de Naciones Unidas, han intervenido las regiones con cultivos de sustitución a través del cacao, información que no es nueva en Colombia como proceso, ya que ha sido visto en gobiernos anteriores. La diferencia en este caso es la modalidad multisectorial buscando un desarrollo alternativo integral y sostenible, pero afec- tando positivamente a las poblaciones con proyectos productivos, infraestructura vial vecinal, formalización y titulación de predios rurales y reforestación donde las familias son el eje del desarrollo para ampliar la frontera agrícola lícita y reduciendo así los espacios de cultivos de coca; se destaca que observan la necesidad de mejorar sus vías como parte de la estrategia. Devida (2016) lo enfoca de la siguiente manera:

Está orientado a mejorar las condiciones económicas, políticas, sociales y ambientales en zonas de tráfico ilícito de drogas, con el fin de desvincular a la población del cultivo de coca y propiciar el desarrollo de una economía productiva ilícita. Para ello, desde un enfoque de desarrollo humano, se busca incidir en las potencialidades de las familias rurales y mejorar sus condiciones de vida. (p. 9).

En el caso colombiano, antes de lograrse la firma de los acuerdos de paz y proyectando la solución para el tema de las drogas, se generó un programa de sustitución de cultivos ilícitos tratando de realizar acciones en el marco de la inversión social en las que se incluye la construcción de vías (red terciaria) y dotación de diferentes servicios públicos para lograr reducir los índices de necesidades básicas insatisfechas; vincular a las familias en áreas de cultivos a la erradicación mediante acuerdos de confianza colectivos y en caso contrario pasar a una erradicación forzosa. La ventaja de aceptar la propuesta de sustitución voluntaria conlleva a la posesión de tierras tras cinco años de demostración de una economía productiva legal; mantener la presencia de la Fuerza Pública para conservar las capacidades de interdicción al delito como medida tanto para generar disuasión a delincuentes como brindar seguridad a los pobladores; fortalecimiento en la investigación y judicialización como herramientas para aplicación de la justicia eficientemente, identificación de redes narcotraficantes y de esta manera evitar la participación de menores de edad en actividades ilegales; tiene un componente de prevención y atención del consumo para una convivencia social y salud mental; finalmente unas reformas institucionales que vincula a la empresa privada y organizaciones no gubernamentales en todo el 
proceso de seguimiento (Presidencia de Colombia, 2015).

En enero de 2020 la Oficina de las Naciones Unidas Contra la Droga y el Delito (UNODC, 2020) realizó un informe de gestión que mide los avances del programa, en este se vincularon 99.097 familias, dentro de ellas 23.986 pertenecen a los departamentos de Cauca, Nariño y Valle del Cauca, notando mayor incidencia en Nariño, siendo el segundo departamento con más beneficiarios, debido a que la actividad económica ilegal a permeado la cultura y tradición de las personas que habitan en la región; sin embargo, el reporte informa que 13.351 familias de la nación, no finalizaron su proceso de inscripción por lo tanto no serían beneficiarios del programa, no obstante el logro fue la erradicación de 35.996 hectáreas de las cuales el $0,4 \%$ persiste la resiembra. El sistema de sustitución proveyó nuevos conocimientos a los recolectores de hoja de coca a través de actividades como mantenimiento de vías terciarias, escuelas y puentes, construcción de viviendas de interés social, mantenimiento de cercas, bibliotecas y espacios comunitarios, así como limpieza y mantenimiento de huertas escolares y puestos de salud; todo esto en procura de que se genere una nueva adaptación. Con relación a los proyectos productivos, buscan:

La intervención de proyectos productivos busca el fortalecimiento de una base económica local y regional en el corto, mediano y largo plazo, que ofrezca fuentes estables y sostenibles de ingresos a través de la implementación de alternativas agrícolas, pecuarias, forestales, de transformación y/o de servicios, identificadas a partir del análisis de las condiciones agroecológicas del territorio, las potencialidades y competitividad del mismo frente a las dinámicas de los mercados, así como de las características de la población. (p. 44).

Confrontando los resultados de Colombia, en Perú condujo a cultivar 64.685 hectáreas de cacao beneficiando a 58.909 personas, también con cultivos de café con 17.459 hectáreas beneficiando a 12.337 personas, prácticamente en cada caso, casi una hec- tárea por persona aprovechada para cultivos lícitos, los cuales después del impulso estatal, fueron comercializados por los mismos agricultores. De otra parte, con relación a infraestructura no se vinculan en el informe del gobierno de Perú sus avances, pero si relacionan el presupuesto que asignan para tal fin (Devida, 2017).

Para el caso de Colombia, el programa está en desarrollo y pareciera que fuera multisectorial como el mencionado por Perú, pero puede evidenciarse que lo concerniente a infraestructura vial como proponen para mejorar la integración nacional, sigue estancada. Así mismo, la situación de cultivos ilícitos, aunque ha mostrado mejoría, los resultados esperados no representan una visión próxima de una real mitigación del narcotráfico, pues, los cultivos ilícitos siguen estando en niveles altos.

Una vez se alcance la integración municipal con la nacional, los caminos conducirán al desarrollo de empresa que puedan modificar las necesidades de la población, al mismo tiempo, permitirá el acceso de la institucionalidad y con ella, el progreso social empujando la educación para modificar la contracultura del narcotráfico a través de una enseñanza edificante. Se ha relacionado la deficiencia en educación existente tanto en el municipio de Tumaco, como los demás de la zona costera nariñense y, por ende, espejo del Pacífico colombiano.

De esta manera se postula que la educación contribuye a modificar la conducta de las personas en favor de la institucionalidad. Para Wilches (2014), la educación es un aspecto que tiene múltiples enfoques que afectan la adecuada contribución de la enseñanza para enfrentar la narcocultura y la corrupción, también confrontando los medios de comunicación y su influencia en la juventud con los programas que tienden a promover la criminalidad, generan una falta de compromiso institucional ante la situación laboral inestable y salarios inadecuados para docentes que se encuentran en áreas vulnerables; a pesar de esto, Wilches (2014) realiza una evaluación adecuada de los efectos del narcotráfico y la necesidad de insistir en 
educación, debido a que han sustituido la legalidad, perjudicando la unidad y el control institucional del territorio para ganar terreno, en donde deberá afrontar los retos que representa en algunas zonas con el machismo, en otras el derroche y la opulencia y en otras el incumplimiento de la ley, de tal manera que la juventud inicie un largo recorrido hacia el deber ser, comentarios que los dice con base en informes de observación de Quiñones (2011):

Distintos autores coinciden en la consideración del "narcomundo" como un sistema esencialmente machista, donde se reproduce en forma caricaturesca el "orden" social instaurado artificialmente sobre la base del supuesto de superioridad masculina. Por lo tanto, es común que en el mundo del narcotráfico se construyan relaciones de género a partir de un conjunto de actitudes y comportamiento que discriminan y marginan a la mujer por su sexo. (p. 214).

Como se observa, el Estado debe ir asumiendo retos, si es necesario a paso lento, para poder llegar a brindar una educación incluyente donde se brinde oportunidades para una educación superior con menos hacinamiento, pero en primera instancia, que incremente el nivel de alfabetismo para ir generando opciones culturales en contraposición a las oportunidades del mundo criminal. En tal sentido, se trata de un reforzamiento, que aunado a lo dicho por Jacinto en Wilches (2014), de una estrategia multisectorial en los municipios que requieren atención:

La escuela debe adoptar estrategias que la lleven más allá de ser un simple escenario de transmisión de conocimientos y la posicionan como un espacio en donde se encuentren alternativas que propicien la reflexión. En caso contrario, estas historias permanecerán como un tema rentable para los medios y un relato en el que los jóvenes serán representados como la población que más accede a las representaciones siempre al límite, abiertamente ilegales, pero legítimas, al momento de ser interiorizadas como una opción de vida riesgosa y válida si se quiere sobrevivir en un mundo dominado por el intercambio de bienes. (p. 227).
Por lo tanto, la gestión del Estado en la transformación cultural de las poblaciones vulnerables que están siendo objeto del conflicto de intereses entre lo legal e ilegal a través del desarrollo, también lleva consigo las oportunidades por medio de la misma gente. Como ejemplo se ha visto el caso de Perú donde la sustitución contribuyó a que las personas vinculadas en actividades ilícitas tuvieran una producción lícita a través de cultivos de cacao y café. Haciendo un paréntesis, es claro que el clorhidrato de cocaína en valor supera en múltiples veces el valor del kilo de hoja de coca, por lo tanto, los programas de sustitución de cultivos concentran su máxima eficiencia en la comparación, como es el caso de Perú, con cultivos de cacao, para que así los cultivadores obtengan una oferta rentable al cambio ante la comparación por kilo de hoja de coca contra un producto legal. Es aquí donde la comunidad se vuelve promotora y comerciante de sus proyectos, cosa que no sucede con el narcotráfico donde los cultivadores son explotados.

Con relación a la integración en la comunidad comercial y garantes de emprendimiento, hubo una situación similar con Panamá. En ese país se realizó un proyecto en el barrio Curundú, era un barrio sumido en la pobreza, pero fueron beneficiados con viviendas de interés social y al mismo tiempo generación de empleo a través de la construcción de sus propias viviendas; de esta manera generando empoderamiento en la población y buscar un nivel de vida adecuado fomentando así el desarrollo social buscando efectividad en las políticas públicas, tal como expresa Pérez (2016):

Curundú es un proyecto de desarrollo urbanístico y social integral, transformador y sostenible de la antigua área residencial y logística en el barrio de Curundú, en la ciudad de Panamá. El barrio, tradicionalmente industrial, con altos índices de pobreza, inseguridad, criminalidad y violencia ha tenido una transformación social gracias a los esfuerzos gubernamentales y privados, contribuyendo al desarrollo sostenible y la construcción de paz en el territorio y siendo un modelo y ejemplo replicable en el país (p. 30).

Con el ánimo que no sea un dato vacío como puede

Pensamiento Americano Vol. 14 - No. 27 - p.p. 95-114 • 2021 • Enero-Junio · Corporación Universitaria Americana • Barranquilla, Colombia · ISSN-e: 2745-1402 $\mathrm{http} / / /$ publicaciones.americana.edu.co/index.php/pensamientoamericano/index 
ser cualquier proyecto de interés social, el gobierno de Panamá (2019) dice con respecto al PIB, que la inversión en infraestructura produce desarrollo social y crecimiento económico, destacando los años 2011 y 2013 donde se diseñó el proyecto, el cual afectó positivamente a la reducción del desempleo:

Los años de su mayor expansión (del 2011 al 2013) coincidieron con importantes inversiones en infraestructura pública tales como la Línea 1 del Metro, Segunda y Tercera Fase de la Cinta Costera, ampliación del Canal de Panamá, Tercera Línea de Transmisión Eléctrica, proyectos de vivienda como la Renovación Urbana de Curundú y construcciones comerciales y residenciales por parte del sector privado (p. 50).

La tasa de desempleo continuó bajando hasta el año 2012, ubicándose en $4.1 \%$, tasa equivalente a un nivel de pleno empleo en la economía (...) El número de desocupados descendió de 101,103 en 2009 a 68,268 personas en $2012,32,835$ desocupados menos. Este panorama se da a consecuencia de un crecimiento económico anual promedio de $8.9 \%$ (...) se sumó un fuerte aumento en el capital físico promovido por la expansión de la inversión pública (Línea 1 del Metro, Cinta Costera II y III, Proyectos del Plan de la Red Vial y de vivienda, como la Renovación Urbana de Curundú).

De esta manera, involucrar a la misma población vulnerable para el desarrollo de su región como método de empoderamiento es una influencia positiva hacia la protección de sus intereses y mitigación del narcotráfico a través del emprendimiento y oportunidad laboral de menor riesgo. En este orden de ideas, Colombia en su zona Pacífica costera puede desarrollar proyectos para mitigar el narcotráfico; en cuanto a geografía, Ecuador cuenta con una región Pacífica de características similares y es aquí donde se dispuso con el Ministerio del Ambiente y Agua, Conservación Internacional Ecuador, la Organización de las Naciones Unidas para la Alimentación y la Agricultura (FAO) y el Instituto Humanista para la Cooperación con los Países en Desarrollo (HIVOS), actividades para promover alternativas que coadyuven a las co- munidades costeras a través de un desarrollo sostenible por medio de proyectos productivos que los vinculen a contribuir al progreso de la región costera. Esta estrategia se basa en la conservación de manglares donde el Pacífico colombiano es rico y permite las actividades de pesca responsables. Colombia, por su parte, con dos océanos tiene un gremio en cada región, un manejo costero integrado el cual busca que la población participe en la explotación de los recursos marinos, pero al mismo tiempo preserven el medio ambiente y unos ejes transversales para la equidad de género y actividades productivas (Ministerio del Ambiente y Agua, 2020). Sobre el aparte de los ejes transversales, se basa en generar transporte marítimo para pasajeros, creación de comedores y restaurantes con productos del mar, desarrollo turístico y cultivos de ostras.

Hace pensar que Colombia podría enriquecer los proyectos productivos en la región Pacífico, para lo cual surgen propuestas como el Corredor Marino del Pacífico Este Tropical (CMAR) donde se incluye como áreas de interés a las Islas de Malpelo y Gorgona, adicionalmente intervienen Costa Rica, Panamá y Ecuador (PNN Colombia, 2017); aquí se busca:

Un instrumento eficaz para la conservación y uso sostenible de la diversidad biológica - en particular de los elementos de la biodiversidad marina y costera - de la región Pacífico Tropical del Este, que involucra las islas del Coco, Galápagos, Malpelo, Coiba y Gorgona, así como el espacio entre ellas. (p. 103).

Así mismo, estas acciones requieren de intervención en tres grupos de trabajo dedicados al turismo, biodiversidad y pesca, destacando en el último grupo de trabajo el desarrollo de un proyecto para mejorar las condiciones de vida de las comunidades locales; sin embargo, no se denotan los resultados de tal gestión, más allá de las normativas y regulaciones. Por lo tanto, la idea será involucrar a las comunidades dentro del mismo desarrollo, pero facilitando las vías para este hecho de manera integral vinculando todos los factores del progreso o desarrollo social que se han comentado. Posiblemente ese vínculo pueda hacerse 
a través de la educación y capacitación de las comunidades en actividades de pesca para mejorar este indicador y promover así la industria que contrarreste la necesidad de vincularse a grupos armados al margen de la ley o actividades de narcotráfico al contar con un trabajo estable. Se menciona a la pesca como factor de desarrollo y oportunidad de mejora ante las cifras de Colombia, pues ha estado en el puesto 81 en pesca bajo captura y 72 en acuicultura entre 229 países que verifica la FAO, lo cual representa un bajo nivel de pesca a pesar de tener el $10 \%$ de las especies conocidas en el planeta aportando un PIB en un 0,17 en 2012 buscando a través planes alcanzar el 4,5\% (AUNAP, 2014; AUNAP, 2018).

Pero no solo puede pensarse a esta región como una zona para pesca por tener muchos peces y turismo por tener costas, más aún cuando no hay intervención estatal decisiva y de la empresa privada de manera agresiva; la zona cuenta con un atractivo potencial minero y de alta biodiversidad geográfica que pueden significar un desarrollo en investigación científica para la búsqueda, entre otras, de soluciones medicinales. Notando que el departamento de Nariño como región minera, puede decirse que hay cerca de 200 títulos mineros, el $58 \%$ corresponde a materiales de construcción y el restante a metales preciosos como el oro, produciendo el 6,43\% de esa actividad extractiva en el país (DNP, 2015b). Quiere decir que, si se logra vincular a la empresa privada con capacidad extractiva, también será promotora de empleo que mitiga la participación de la población al narcotráfico. Se agrega que, al participar el Estado con infraestructura, también será promotor de empleo directo para este fin y de manera indirecta cuando el comercio llegue sin temor a los grupos armados organizados a la región.

Con base al trabajo que registra en la Escuela Superior de Guerra elaborado por Serrano (2020), si se siguen las estrategias propuestas de: fortalecer el sistema penal para los delitos de narcotráfico aumentando así el riesgo de pertenecer a una agrupación de transporte de estupefacientes; $y$, aumentar el poder naval incrementando la eficiencia de captura, am- bos como factores de mitigación del fenómeno como manera preventiva y disuasiva, aunado a los esfuerzos estatales para incrementar el desarrollo social, se lograría una verdadera afectación al delito, pues el desarrollo brinda oportunidades e incrementa las opciones de decisión ante la criminalidad.

En caso de darse un desarrollo social y sostenible ante la diversidad de recursos con que cuenta la región contribuyendo significativamente a la mitigación del narcotráfico, también cambiaría la concepción geopolítica. López (2012) manifiesta que en primera instancia existirá una comunicación con el Heartland de Colombia, a medida que las vías vayan cerrando espacios de comunicación, la población irá teniendo oportunidad al desarrollo y una real integración con el país, notando que el heartland sea la ciudad de Bogotá como capital política y administrativa; quiere decir que su principal vínculo es el poder donde fluye la política, la economía la ideología y la dirección hacia el poder militar, donde se busca el equilibrio de estos poderes y por ello, la integración de la región Pacífico mediante vías de desarrollo, multiplicará la gobernabilidad. Si Bogotá es el Heartland, el Hinterland vendrían siendo todos los municipios costeros de la región Pacífico, que sirven de reserva y fuente de crecimiento y desarrollo según López (2012) y es por esto por lo que son fundamentales la rehabilitación e interés estatal para pasar al control institucional. Siguiendo con López (2012) quien se basó en el autor geopolítico del siglo XIX Karl Haushofer, los departamentos de Chocó y de Nariño son fronterizos, por lo tanto, la conexión con el centro del poder del país es fundamental para incrementar los vínculos limítrofes y disminuir el choque que pueda existir entre intereses nacionales de países y mejorar las relaciones diplomáticas.

Tanto el heartland, hinterland y fronteras necesitan de una comunicación estable a través de vías aéreas, fluviales, férreas, carreteras y telecomunicaciones; como se ha mencionado solo existen dos carreteras y varias arterias fluviales, siendo necesaria la oportunidad de generar canales de comunicación entre municipios también por vía terrestre, donde las 
carreteras se convierten en posibilidades de inversión por parte de la industria privada y mejora la interacción gobierno-población, para que la cordillera no represente una separación (López, 2012):

Las prioridades en el diseño del sistema vial colombiano han estado, y en muchas partes continúan, altamente afectadas por asuntos ajenos a los aspectos técnicos. Las razones son claras: por un lado, una estructura centralista al extremo, por otro, dos aspectos: primero, la ausencia de una conciencia geopolítica respecto a las necesidades del país; segundo, una clase política que siempre ha antepuesto sus intereses personales al interés de la nación. Se dio prioridad a aquellos sobre éste al diseñar las carreteras. La vía debía pasar no por donde las especificaciones técnicas lo demandaban, sino, por aquellos pueblos que componían el electorado del político de turno, o por aquellas tierras que pertenecían al mismo personaje y/o a su familia. (p. 84).

Se reitera que las carreteras son la opción de vincular al Estado con todo el territorio y de esta forma sus fuerzas armadas serán más efectivas para que puedan ejercer el poder ejecutivo, legislativo y judicial en todo el territorio. Esto acerca más al concepto de la geopolítica contemporánea, la cual vincula elementos con relación al poder, Ferro y Castaño (2016) cuando pronuncian a Yves Lacoste dicen:

El término "geopolítica”, utilizado en nuestros días de múltiples maneras, designa en la práctica todo lo relacionado con las rivalidades por el poder o la influencia sobre determinados territorios y sus poblaciones: rivalidades entre poderes políticos de todo tipo - no solamente entre Estados, sino también entre movimientos políticos o grupos armados más o menos clandestinos $-\mathrm{y}$, rivalidades por el control o la dominación de territorios de mayor o menor extensión. Los razonamientos geopolíticos ayudan a comprender mejor las causas de tal o cual conflicto, dentro de un país o entre estados, pero también a proyectar los que puedan tener lugar, por tanto, las consecuencias de aquellas luchas en países más o menos alejados y algunas veces también en otras partes del mundo. (p.117).

Quiere decir, que la relación entre geopolítica y poder, en especial a escala regional o local, debe propender por reducir la problemática existente en la región Pacífico para de esta manera aumentar su capacidad de coordinación y necesidades en el ámbito estratégico nacional, teniendo en cuenta que por ejemplo, el departamento de Nariño: será la conexión con la diplomacia ecuatoriana, incrementará el PIB interno a través de productos productivos y pesca que puede tecnificarse e industrializarse; además de generar desarrollo con vías terrestres que acerquen la región a la producción y centro de poder nacional. Entonces, la problemática del narcotráfico como multiplicador y fenómeno de sostenimiento de grupos armados al margen de la ley, será confrontado por el poder del Estado, pero no de manera reactiva a través del ejercicio de sus Fuerzas Militares y de Policía, sino del factor multiplicador e integrador regional del desarrollo social, que irá mitigando los efectos ilegales mediante el ingreso de educación, salud, vivienda y generación de empleo, entre otros, a través de las posibilidades que surjan de la infraestructura con empleos directos para construcción. La mitigación del narcotráfico necesita vincular en su propuesta el factor social de desarrollo, de otra parte, la problemática será redundante si no se generan opciones de elegir entre la criminalidad o las vías legales.

\section{Marco teórico \\ Antecedentes}

En la realización del proceso de revisión de antecedentes, se encontró una serie de trabajos relacionados con el tema de investigación, los principales hallazgos en la revisión documental dieron una visión amplía de la influencia de la pobreza en el aumento de los actos delictivos y la importancia del desarrollo social para mitigar el alto índice de criminalidad en la zona objeto de estudio.

El primero de los referentes de investigación es la investigación de Villamizar (2020), con su artículo "La reforma agraria: la paz con las farc, un compromiso aplazado de nuevo", en donde el autor hace referencia a 
influencia que tiene la guerra (producto del narcotráfico y del deseo de tener el control territorial) y el aumento de la pobreza en los lugares donde se intensifica la producción y el tráfico de droga en el país. El artículo concluye que el proceso de paz ha sido de vital importancia para la disminución de la violencia y la pobreza en el país, donde el campo deje de ser un escenario de confrontación de ejércitos y se transforme en un espacio económico que garantice la autonomía agroalimentaria del país, pero, la paz también ha puesto en la escena pública el problema principal de Colombia: la deficiente distribución de la propiedad de la tierra, que uno de los grandes problemas que tiene la población indígena y campesina en el país.

Para los autores Pineda y Rodríguez (2017), "Criminalidad en la ciudad de Bogotá: Una mirada desde la privación económica”, que tenía por objetivo mostrar las fallas que tiene el Estado en el diseño de políticas públicas dirigidas a mejorar la calidad de vida de los ciudadanos. En este estudio los autores realizaron una comparación con la ciudad de los Ángeles, que desde el año 2003 ha venido consolidando un programa de reducción de pandillas, y ha mejorado el bienestar social de la ciudad. Esta investigación concluye que, en la ciudad de Bogotá, es indispensable diseñar un programa de política públicas que integre los factores (sociales, económicos y culturales) para mejorar los índices de pobreza y que disminuyan losíndices de criminalidad en la ciudad.

El artículo de los autores Galvis, Moyano y Alba (2017), titulado "La persistencia de la pobreza y sus factores asociados" tiene por objetivo analizar las condiciones de pobreza de la Región Pacífica, desde una perspectiva multidimensional, la investigación demostró que según el índice de pobreza multidimensional (IPM), la región Pacífica tiene los mayores índices de pobreza en el país, después del Caribe y la región de Orinoquia-Amazonia. Es decir, que la mayoría del territorio de la Región Pacífica se encuentra envuelto en una trampa de pobreza, con altos índices de analfabetismo y el aumento de las actividades ilegales como medio de escape de la pobreza que agobia la región.

Otro antecedente de investigación es el artículo "Re- primir o regular: el falso dilema de las políticas de drogas" del autor Garzón, (2015), que analiza la influencia que tiene la política de droga implementada por el Estado, en la seguridad y disminución de la violencia en los territorios. Para el autor, no solo el narcotráfico es la causa del aumento de la ilegalidad y la violencia, existe un conjunto de variables estructurales y coyunturales que también influyen en las altas tasas de homicidio y de presencia de organizaciones criminales. El artículo finaliza con cuatro grandes conclusiones sobre el tema: primero, no hay una relación única entre las drogas, la violencia y el crimen. Segundo, a pesar de la percepción de que la inseguridad estáfuertemente vinculada a ellas, a lo largo de la región hay mercados que funcionan con bajos niveles de violencia y delito. Tercero, cuando esta relación se expresa de manera intensa, generalmente se encuentra una débil presencia institucional y la yuxtaposición con otras actividades criminales y Cuarto, las intervenciones del estado mediante la aplicación drástica y deliberada de las leyes de drogas pueden llegar a ser un factor perturbador, que genere las condiciones para el aumento de la violencia y el crimen.

\section{Bases teóricas.}

Las bases teóricas se fundamentan en el Desarrollo Humano, tiene por objetivo alcanzar las libertades humanas, es decir, la libertad de desarrollar todo el potencial de cada vida humana, no solo el de unas pocas ni tampoco el de la mayoría, sino el de todas las vidas de cada rincón del planeta (PNUD, 2017).

La teoría del Desarrollo Humano surge en la década de los noventa y tiene sus raíces en la preocupación que despiertan las críticas al enfoque economicista de los estudios del desarrollo y en la búsqueda por integrar en el análisis los aspectos sociales de la población. Su principal representante el autor Amartya Sen, sintetiza las principales ideas de su pensamiento en entender y abordar el desarrollo como medio para potencializar las capacidades y libertades del ser humano (Sen, 2000).

En la concepción teórica propuesta por Sen (2000), se define al desarrollo "como un proceso de expansión

Pensamiento Americano Vol. 14 - No. 27 - p.p. 95-114 • 2021 • Enero-Junio · Corporación Universitaria Americana • Barranquilla, Colombia · ISSN-e: 2745-1402 $\mathrm{http} / / /$ publicaciones.americana.edu.co/index.php/pensamientoamericano/index 
de las libertades reales de las que disfrutan los individuos", donde "la libertad real (...) está representada por la capacidad de la persona para conseguir varias combinaciones alternativas de funcionamientos" (pág. 81), que permite a las personas en los entornos sociales, económicos, culturales, políticos y medioambientales que se encuentre, realizar cosas valiosas para ellos y sus familias (Sen, 2000).

Amartya Sen, expresó que para hablar del desarrollo de una sociedad hay que analizar la vida de quienes la integran, que no puede considerarse que hay éxito económico sin tener en cuenta la vida de los individuos que conforman la comunidad. El desarrollo es entonces el desarrollo de las personas de la sociedad (Sen, 2000).

Para el autor, cada persona, en función de sus características, origen y circunstancias socioeconómicas con las que convive, tiene la capacidad para hacer ciertas cosas que valorará por diferentes motivos. Tal valoración puede ser directa o indirecta: la primera está en función de aquellos elementos que implican que podrá enriquecer su vida, es decir que le permitirán tener una mejor calidad de vida, como estar bien nutrido o sano; la segunda tiene que ver con la posibilidad de contribuir más y mejor en la producción. De esta manera, la perspectiva de la capacidad humana es más abarcativa que la teoría del capital humano, esta última una expresión más limitada de la capacidad humana (Sen, 2000).

Es decir, para Sen (2000), las capacidades están relacionadas a las libertades fundamentales que poseen los individuos, que les permite lograr distintos estilos de vida que le permitan satisfacer las necesidades básicas que le concedan la posibilidad de vivir dignamente.

Es decir que el desarrollo humano está condicionado por el entorno económico, social, político, cultural y ambiental del territorio donde se desarrolla, por lo que es necesario la integración interinstitucional a la hora de diseñar políticas públicas que garanticen el sostenimiento de la población en condiciones dignas.

Uno de los sectores que más limita el desarrollo en las regiones es el económico, que abarca una serie de factores en las dimensiones productiva, social, política y ambiental, que en su conjunto generan el crecimiento sostenido de un país (CEPAL, 2012).

En países como Colombia, donde el tráfico de drogas se ha convertido en un problema latente, que, aunque genera empleo, agrega valor y mueve un gran volumen de dinero, esta economía ilegal afecta directamente el desarrollo. No es posible tener un desarrollo sostenible basado en la ilegalidad (PNUD, 2011).

También se resalta la importancia de términos como gobernabilidad y gobernanza en los países de América Latina. El autor Camou (2001), define la gobernabilidad como un estado de equilibrio dinámico entre el nivel de las demandas societales y la capacidad del sistema político (estado/gobierno) para responderlas de manera legítima y eficaz.

La gobernanza, se refiere al proceso de toma de decisiones, de negociación de prioridades, de utilización del poder, y a los valores expresados en el proceso mismo (Launay, 2005).

En la actualidad es muy común ver que en los territorios se presta más atención a los temas de gobernabilidad que a los de gobernanza, es decir el Estado se preocupa más en cómo se gobierna, que por los procesos y toma de decisiones que reflejen una mejora en el desarrollo y seguridad ciudadana de las regiones.

\section{OBJETIVOS}

- Identificar una estrategia que pueda aplicarse desde la función pública para mitigar la criminalidad y fomentar el desarrollo social en la región Pacífico colombiano.

- Describir la evolución social del Pacífico colombiano a causa del fenómeno de los factores de inestabilidad que impiden el desarrollo.

- Examinar el rol de la gobernanza para mitigar los factores de riesgo y proyectar una perspectiva de solución desde el ámbito social. 
- Proponer posibles soluciones ante la problemática de la región Pacífico colombiano desde el apoyo de las Fuerzas Militares hacia la consolidación institucional del territorio.

\section{METODOLOGÍA}

Se realizó una investigación científica de tipo cualitativo, cuantitativo y descriptivo; una parte de este artículo contó con una investigación desarrollada para la Escuela Superior de Guerra que buscaba una cercanía sobre la percepción del narcotráfico, aquí emplearon entrevistas a una comunidad de internos que han sido capturados por transportar sustancias estupefacientes por vía marítima en el Pacífico colombiano y esto fue contrastado con una encuesta realizada a 251 miembros de la Armada de Colombia distribuidos en 65 oficiales, 161 suboficiales, 19 Infantes de Marina, cinco integrantes de la Armada de Colombia de categoría civil y un Oficial en uso de buen retiro que de manera voluntaria en el lapso del 1 al 4 de abril de 2020, cuya confrontación arrojó los datos de estudio para identificar al desarrollo social como una necesidad para cambiar la contracultura. Así mismo, dentro de este estudio se tuvo en cuenta informes de las Naciones Unidas, del gobierno de Colombia con sus institutos, observatorios y ministerios y de manera clara y objetiva diferentes artículos que permiten encontrar el tema central como son aportes del Banco Mundial, estudios de geopolítica, críticas al narcotráfico y lo que concierne a la gobernanza y gobernabilidad, arte y acción para diferenciar lo que debería ser y lo que puede hacerse.

\section{CONCLUSIONES}

La región litoral del Pacífico colombiano es una oportunidad para conducir la gobernabilidad y recuperar el tejido social en contra de la criminalidad. Integrar la región con el poder nacional, conducirá a facilitar las ordenanzas que se requieran desde el Ejecutivo para con la población, ya que habrá un reconocimiento legítimo de la institucionalidad por encima de la criminalidad, porque estará aportando a la salud, educación, infraestructura, alimentación, desarrollo y seguridad.
Para lograrlo se requiere de un esfuerzo de los gobernantes locales para que puedan dar prioridad a los proyectos de infraestructura, de tal forma que se tengan las locaciones adecuadas para conformar centros de salud y educación, que puedan acercar las comunidades a los entes territoriales municipales. Así mismo, debe existir una conexión con el interior del país y las regiones entre sí, si bien profundizando en un desarrollo del transporte fluvial, con carreteras y puentes que vuelvan competitiva e interesante la región.

El índice de desarrollo humano y de necesidades básicas insatisfechas de los municipios del litoral, han demostrado la ineficiencia en materia de políticas públicas. Los indicadores de salud, educación e infraestructura han estado por décadas con bajo rendimiento en comparación con la capital del país, siendo muestra que el centralismo ha profundizado el desarrollo social desde el heartland hasta el hinterland. Es necesario que la población sienta que existe una preocupación desde el gobierno nacional para con su desarrollo y de esta manera, ir reduciendo espacios a la criminalidad.

La contracultura generada por el narcotráfico ha tergiversado lo correcto que significa el trabajo honrado. Desde la televisión con programas que incentivan el comportamiento ilegal en la juventud, promueven una conciencia hacia la ilegalidad como opción de vida. La falta de educación en la región y la existente sin politizar, son factores que pueden tergiversar la realidad permitiendo a la juventud identificar su pertenencia a grupos al margen de la ley como proyecto de vida al incrementar la ignorancia y desconocer los beneficios del aprendizaje. A medida que el desarrollo ingrese en la región, irá restando espacio a lo ilegal, de otra manera una región sin oportunidades será una perpetuidad de conductas y hechos punibles constantes.

Es posible que la empresa privada promueva el desarrollo, lo que generará nuevos empleos y reducirá el reclutamiento forzado. Ese ingreso mejorará la infraestructura y reducirá los índices de desempleo, de un lado están los empleos directos producto de su vinculación 
empresarial y de otro los empleos indirectos a través de diferentes servicios como mensajería, transporte y construcción, además de acercar la población a cubrir sus servicios públicos. También podrá explorar y explotar de manera eficientey sostenible los recursos existentes que brinda la geografía, haciendo más competitiva la región y de interés para el comercio mundial.

La empresa privada unida al Estado, son proveedores de proyectos productivos que la región necesita para que los cultivadores de hoja de coca tengan una oportunidad real de sustitución de cultivos y de manera confiada, la población tendrá un empoderamiento de sus propios terrenos sin temor a captura.

A medida que el desarrollo social vaya fomentando el empleo, salvaguardando la seguridad alimentaria y de salud, los habitantes irán soltando los cabos que los amarra a los cultivos ilícitos y la cultura ilegal. La recuperación del tejido social y el vínculo entre la diferenciación de lo legal e ilegal producto de una ley rigurosa y una presencia naval que tranque el tránsito de transporte de sustancias estupefacientes, son factores de riesgo que serán percibidos para optar por una toma de decisiones acertada por parte de la gente para alcanzar vías legales de desarrollo y cubrimiento de sus necesidades. Todo esto resume que, sin importar el tipo de acciones estatales para enfrentar la amenaza del narcotráfico, bien sea la legalización, normalización o prohibición de las drogas, ante la ausencia del desarrollo social, siempre será un comburente que potenciará la criminalidad.

Es necesario una intervención multisectorial acompañada por las Fuerzas Militares en este proceso de largo alcance para blindar la inversión en desarrollo social; esto requiere de potenciar las capacidades militares que le permita al Estado con seguridad construir carreteras, escuelas y hospitales para ir siendo semilla de lo que a futuro podrábrindar una región sosteniblemente explotada contribuyendo a la economía nacional e inmersa en los intereses nacionales.

\section{Referencias}

Alcaldía de Tumaco. (2018). Análisis de la situación de salud con el modelo de los determinantes sociales ASIS. https://www. minsalud.gov.co/sites/rid/Lists/BibliotecaDigital/RIDE/ VS/ED/PSP/asis-distrital-tumaco-2019.pdf

Aragón, F. (2010). Colombia y su poder geopolítico. [Tesis de pregrado, Universidad Javeriana]. Archivo digital. https://repository.javeriana.edu.co/bitstream/handle/10554/7704/ tesis369.pdf;jsessionid=A080E8AAFC9D5A73B3B291F1EFCF93E2?sequence=1

AUNAP. (2014). Colombia. Pesca en cifras - 2014. https://aunap. gov.co/wp-content/uploads/2016/05/Pesca_en_cifras.pdf

AUNAP. (2018). Plan Estratégico Institucional. Pacto por la pesca, pacto por la acuicultura. https://www.aunap.gov.co/index. php/plan-estrategico-institucional

Banco Mundial. (2014, 03 de septiembre). Está demostrado: con menos desigualdad se tiene menos crimen. https:/www.bancomundial.org/es/news/feature/2014/09/03/latinoamerica-menos-desigualdad-se-reduce-el-crimen

Camou, A. (2001). Los desafíos de la Gobernabilidad. (Estudio preliminar y compilación). Editorial Plaza y Valdés.

CEPAL. (2012). La hora de la igualdad: brechas por cerrar, caminos por abrir. https://www.cepal.org/es/publicaciones/13309-la-hora-la-igualdad-brechas-cerrar-caminos-abrir-trigesimo-tercer-periodo.

DANE. (2018a). ¿Cuántos somos? https://sitios.dane.gov.co/ cnpv/\#!/

DANE. (2018b). Necesidades básicas insatisfechas. https://www. dane.gov.co/index.php/estadisticas-por-tema/pobreza-y-condiciones-de-vida/necesidades-basicas-insatisfechas-nbi

DANE. (2019). Medida de pobreza multidimensional municipal Censo Nacional de Población y Vivienda. https://www.dane. gov.co/index.php/estadisticas-por-tema/pobreza-y-condiciones-de-vida/pobreza-multidimensional

Devida. (2016, 15 de marzo). El Marco Institucional y de Políticas de Desarrollo Alternativo en el Perú. https://www.unodc. 
org/documents/peruandecuador/DocumentosDA/PeruColombiaDA/cacao_unodc.pdf

Devida. (2017). Informe de evaluación de resultados del programa presupuestal desarrollo alternativo integral sostenible - PIRDAIS 2016. Gobierno de Perú. https:/www.devida.gob.pe/ publicaciones/-/asset_publisher/qFALrjP4e3Cl/content/ informe-de-evaluacion-de-resultados-del-programa-presupuestal-desarrollo-alternativo-integral-y-sostenible-pirdais-2016?inheritRedirect=false

DNP. (2015a). Desempeño fiscal de los departamentos y municipios 2015. https://colaboracion.dnp.gov.co/CDT/Desarrollo\%20Territorial/Desempe\%C3\%Blo\%20Fiscal\%20 2015\%20V.2016.11.09.pdf

DNP. (2015b, 30 de mayo). Pacífico: desarrollo socioeconómico con equidad, integración y sostenibilidad ambiental. https://colaboracion.dnp.gov.co/CDT/Desarrollo\%20Territorial/D.\%20Pac\%C3\%ADfico_Desarrollo\%20socioecon\%C3\%B3mico\%20con\%20equidad,\%20integraci\%C3\%B3n\%20y\%20sostenibilidad\%20ambiental.pdf

Ferro, G. \& Castaño, Ó. (2016). Geopolítica contemporánea y análisis de factores relevantes a escala global. Razón Crítica 3, 111144. doi: http://dx.doi.org/10.21789/25007807.1235

Galvis, L. A., Moyano, L. M. \& Alba, C. A. (2017). Estudios Sociales del Pacífico Colombiano: La persistencia de la pobreza y sus factores asociados en el Pacífico Colombiano. Colección Banco de la República Luis Ángel Arango. https://repositorio.banrep.gov.co/bitstream/handle/20.500.12134/9298/ LBR_2017-12.pdf?sequence=1\&isAllowed=y.

Garzón, J. (2015). Reprimir o regular: el falso dilema de las políticas de droga. Friederich Ebert Stiftung. http://library.fes.de/ pdf-files/bueros/kolumbien/12266.pdf

Gobierno de Panamá. (2019). Consejo de Gabinete. Resolución de Gabinete No. 147. https://www.gacetaoficial.gob.pa/pdfTemp/28931_A/GacetaNo_28931a_20191231.pdf

González, F. (2009). Gobernabilidad y Gobernanza. Las relaciones intergubernamentales: concepto y marco teórico. El contexto y concepto. Características. Modelo. Estructuras. Castilla: Escuela de Administración Regional. http://pagina.jccm.es/ ear/descarga/AlT10.pdf

Head, B. W. (2008). Three lenses of evidence-based policy. The
Australian Journal of Public Administration, 67(1), 1-11. doi:10.1111/j.1467-8500.2007. 00564.x

Instituto de Ciencia Política [ICP]. (2018). Una apuesta por la competitividad de Tumaco. http:/www.icpcolombia.org/ dev/wp-content/uploads/2018/06/18.06.08-DIGITAL-TUMACO.pdf

Launay, C. (2005). La gobernanza: Estado, ciudadanía y renovación de lo político. Origen, definición e implicaciones del concepto en Colombia. http://biblioteca.clacso.edu.ar/Colombia/ cinep/20100925104922/lagobernanzaControversial85.pdf.

López, J. (2012). El Estado como núcleo vital. El caso colombiano. Revista Universidad Eafit No. 92, 79-90. doi: http://dx.doi. org/10.21789/25007807.1235

Min educación. (2018). Tasa de analfabetismo en Colombia a la baja. https://www.mineducacion.gov.co/1759/w3-article-376377.html?_noredirect=l\#: : :text=Seg\%C3\%BAn\%20 la\%20Gran\%20Encuesta\%20Integrada,la\%20zona\%20 rural\%20es\%20analfabeta

Ministerio de Transporte. (2020). Proyectos de infraestructura. https://gpi.mintransporte.gov.co/reports/strategicTop/todas/todas

Ministerio del Ambiente y Agua. (2020). Proyecto Marino Costero. https://www.proyectomarinocostero.com.ec/manejo-costero-integrado/

Observatorio de Drogas de Colombia y Min Justicia. (2014). Dinámica de los cultivos y producción de coca en Colombia con énfasis en la región fronteriza con Ecuador. 33. http://www. odc.gov.co/Portals/1/Docs/pecig/estudiosInv/DinCultProdCocaRegi\%C3\%B3nFronteraEcu.pdf

Observatorio de drogas de Colombia. [ODC]. (2016). Caracterización regional de la problemática asociada a las drogas ilícitas en el departamento de Nariño. http://www.odc.gov.co/Portals/1/politica-regional/Docs/2016/RE0639_narino.pdf

Parra, M., Higuera, L. \& Rodríguez, A. (2019). Evaluación de potencial de crecimiento verde. Departamento de Nariño. Pasto: Global Green. https://gggi.org/site/assets/uploads/2019/10/ EPCVNari\%C3\%Blo.pdf

Pérez, M. A. (2016). Post-acuerdo y objetivos de desarrollo sostenible: educación para la paz, una oportunidad para Co- 
lombia propuesta de curso de verano en la Universidad EAFIT, basada en el Barco de la Paz. Medellín: Universidad EAFIT. https://repository.eafit.edu.co/bitstream/handle/10784/8724/MariaAntonia_PerezMejia_2016.pdf?sequence $=2$

Pineda, M. \& Rodríguez, B. (2017). Criminalidad en la ciudad de Bogotá: Una mirada desde la privación económica. [Tesis de pregrado, Universidad de la Salle]. https://ciencia.lasalle.edu. co/cgi/viewcontent.cgi?article=1324\&context=economia

PNN Colombia. (2017). Proyecto de inversión en el corredor marino del Pacífico Este Tropical (CMAR). Estudio de Pre-factibilidad.http://cco.gov.co/

PNUD. (2011). Informe sobre el desarrollo mundial 2011. https:// wwwl.undp.org/content/undp/es/home/librarypage/hdr/ human_developmentreport2011.html.

PNUD. (2017). Desarrollo humano significa que cada persona alcance todo su potencial. https://wwwl.undp.org/content/undp/es/home/blog/2017/3/21/Human-development-means-realizing-the-full-potential-of-every-life.html.

Presidencia de Colombia. (2015, 22 de septiembre). Los 6 frentes del Plan Integral de Sustitución de Cultivos. https:// www.minjusticia.gov.co/Portals/0/Ministerio/Sustituci\%C3\%B3n\%20de\%20cultivos\%20-\%20Hoja\%20de\%20 datos\%20(1).pdf

Presidente de la República. (2018, septiembre). Plan Nacional de Desarrollo 2018-2022. Colombia. https://colaboracion.dnp. gov.co/CDT/Prensa/Resumen-PND2018-2022-final.pdf

Quiñones, B. (2011). Mujer y narcomundo: una mirada desde los estereotipos de mujer y la feminización de la pobreza. Bogotá: Instituto de Estudios Comunicación y Cultura, Universidad Nacional de Colombia.

Sánchez, M. \& Caballero, M. (2019). Índice de desarrollo humano modificado por la variable de acceso a salud. [Tesis de pregrado, Universidad de la Sabana]. Archivo digital. https://intellectum.unisabana.edu.co/bitstream/handle/10818/36748/ Sanchez_Caballero\%20\%282019_1\%29\%20Indice\%20Desarrollo\%20Humano\%20VF.pdf?sequence $=1$ \&isAllowed=y

Secop i. (2020, 22 de febrero). Servicio Electrónico de Contratación. https://www.contratos.gov.co/consultas/
Sen, A. (2000). Desarrollo y libertad. Barcelona. Editorial Planeta.

Serrano, J. (2020). Propuesta para fortalecer la Estrategia de lucha antidrogas en el transporte por vía marítima en el Pacífico colombiano. Bogotá, Colombia: Escuela Superior de Guerra.

UNDP. (2020). ¿Qué es el Índice de Pobreza Multidimensional? http://hdr.undp.org/en/node/2515\#: :text=El\%20 \% $3 \% 8$ Dndice\%20de\%20Pobreza\%20Multidimensional\%20(IPM)\%20identifica\%20m\%C3\%BAltiples\%20carencias\%20a,y\%20el\%20nivel\%20de\%20vida.

UNODC. (2012). Sistema Integrado de Monitoreo de Cultivos Ilícitos 2011. https://www.unodc.org/documents/crop-monitoring/Colombia/Censo_cultivos_coca_2011.pdf

UNODC. (2019). Monitoreo de territorios afectados por Cultivos Ilícitos 2018. https://www.unodc.org/documents/colombia/2019/Agosto/Informe_de_Monitoreo_de_Territorios_ Afectador_por_Cultivos_Ilicitos_en_Colombia_2018_.pdf

UNODC. (2020). Informe N. 20. Programa Nacional Integral de Sustitución de Cultivos Ilíticos - PNIS. Bogotá: ONU.https:// www.unodc.org/documents/colombia/2020/Abril/INFORME_EJECUTIVO_PNIS_No._20.pdf

Villamizar, J. (2020). La reforma agraria: la paz con las farc, un compromiso aplazado de nuevo. Anuario Colombiano de Historia Social y de la Cultura, 47(1), 231-263.

Wilches, J. (2014). ¿Y educar para qué? Representaciones mediáticas de narcocultura en los modelos del progreso económico y prestigio social. Desafíos, 26(1),199-234.
2021, Vol. 14(27) 95-114. (CThe Author(s) 2021 Reprints and permission: www.americana.edu.co http://publicaciones.americana.edu.co/index.php/pensamientoamericano/index 